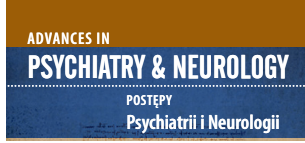

Correspondence to:

Agnieszka Chojak

SWPS University

Warsaw, Poland

ul. 3 Maja 55

13-230 Lidzbark

e-mail: achojak@st.swps.edu.pl

Accepted: 22.01.2021

\section{THE EFFECTIVENESS OF ACCEPTANCE AND COMMITMENT THERAPY-BASED INTERVENTION IN THERAPY FOR MENTAL HEALTH DISORDERS - CASE STUDY}

\author{
Agnieszka Chojak, Anna Papińska
}

SWPS University, Warsaw, Poland

\begin{abstract}
Purpose: This case study exemplifies the effectiveness of Acceptance and Commitment Therapy (ACT) based intervention in the socially excluded patient. The hypothesis tests the use of the ACT based intervention as the therapeutic programme for individuals with a GAD diagnosis and with sub-threshold levels of psychopathological symptoms.

Case description: A female patient, aged 52, with increased levels of anxiety and depression symptoms, complaining about excessive worrying, after an initial interview took part in a 12-session intervention programme based on ACT. She was examined twice with WAQ-II, STAI, AAQ-II ,VLQ and DASS-21 questionnaires. The results showed decrease in problematic symptomatology and improvement in psychological flexibility.

Comment: The use of an ACT-based intervention can be a useful method in the early stages of mental disorders. Further quantitative research into the effectiveness of this type of intervention is recommended, including online programs or self-help guides.

Key words: psychological flexibility, ACT therapy, transdiagnostic approach, therapy of mental disorders.
\end{abstract}

\section{PURPOSE}

Mental disorders are an important public health issue all over the world [1]. The World Mental Health (WMH) Survey Initiative of the World Health Organisation (WHO) reported that these disorders have a significant adverse impact on human functioning as they prevail both in developed and in less-developed countries throughout the world [1]. The direct consequences and societal costs of mental disorders comprise, among others, of impaired functioning, reduced longevity of human life and healthcare expenses [2]. Despite the prevalence of mental disorders, only a small percentage of individuals receive appropriate treatment [3]. However, the early diagnosis of the onset of psychopathological symptoms and mental health prevention programmes have the potential to reverse the societal costs of mental disorders [1]. Due to the fact that the majority of mental disorders go untreated and that there is a vast number of Diagnostic and Statistical Manual (DSM) subthreshold premorbid unaddressed populations, the urgent need to implement effective evidence-based intervention emerges [4]. Additionally, in order to enlarge the applicability of the intervention programme, it should address symptomatology across the DSM-defined categories of disorders - aiming at the development of symptomatology in a transdiagnostic approach. In recent decades, the nosology applied in subsequent editions of the DSM has received some criticism due to its evident shortcomings [5]. It is based on the covariation of symptoms in a clinical population and thus is unable to distinguish between two independent aetiologies based upon disparate psychobiological mechanisms, because of identical symptom display $[1,6]$. Conversely, symptoms may be different but based on the same aetiology and will therefore be classified into different DSM categories. This criticism is in line with the wide body of research reporting the comorbidity of different DSM disorders. For example, anxiety disorders (generalized anxiety disorder [GAD] and social anxiety) and depression share a similar phenomenology and have a tendency to co-occur [7]. Additionally, the DSM excludes severe forms of psychopathology, when the benchmarks for number and duration of symptoms are not met [5]. According to neurobiological research, many psychopa- 
thological symptoms are "continuous with normalcy" [8] and thus exhibit specific connotations with neurobiological functioning in pre-morbid populations $[9,10]$. Some recent initiatives address the limitations of the DSM taxa, promoting the development of remodelled mental health nosology focused on transdiagnostic factors of psychopathology $[11,12]$. The most common types of mental disorders in general population across surveys are the following: anxiety disorders, including panic disorder, phobias, GAD, and PTSD. Despite its prevalence, GAD constitutes one of the most difficult disorders to diagnose as its characteristic symptoms, namely worry and anxiety, are universal human experiences [13]. According to Tom Borkovec's Avoidance Model of Worry and GAD (AMW) [14], worry is a linguistic activity based on thoughts that inhibit somatic and emotional activation. Therefore worry can be interpreted as an ineffective attempt at cognitive problem-solving and removing of a potential threat, at the same time avoiding the unwanted somatic and emotional experience connected with the process of fear confrontation [14]. According to AMW, the etiological and maintenance factors of GAD may be the impact of poor interpersonal skills and early lifetime events such as past trauma or insecure attachment style. In AMW, worry is conceptualised as a form of avoidance [15]. The function of worry in an individual with GAD is to decrease the perceived possibility of the occurrence of negative events and to reduce a sense of uncertainty and unpredictability $[15,16]$. While excessive or unrealistic worry is present in GAD [13], and according to the research its function may be to diminish internal distress by decreasing the experience of uncertainty, the exposure to uncertainty may lead to more optimal functioning and thus it should be incorporated into treatment [15]. Due to the WHO report's recommendations [17] new ways of understanding psychopathology and combating its consequences need to be found. The therapy model responding to the problems indicated above is acceptance and commitment therapy (ACT) - a "third-wave" cognitive behavioural therapy model, which targets experiential avoidance in the form of worrying and avoiding experience in general, by the processes of acceptance and mindfulness and the agenda of abandoning control [18]. ACT emphasises contextual and experiential facets of psychological experience by encouraging mindfulness, the acceptance of internal experience, and engagement in action in line with chosen values, as opposed to habitual restrictions in activities that are caused by excessive worry and experiential avoidance in general [18]. In other words, this is a model of intervention that uses mindfulness and acceptance techniques, along with commitment and behaviour change strategies, in order to act in compliance with the chosen values despite the emotional pain and presence of life adversities [19]. ACT is based on a model of psychological flexibility defined as the ability to contact the present moment with- out unnecessary defences and with full awareness; and to change or persist in behaviour consistent with one's chosen values while doing so [19]. On the contrary, psychological inflexibility based on a constant rigid pattern of reacting to inner experience that limits the array of behaviours and possibility of achieving the external support is conceptualised as a factor leading to psychopathology and a lowering of the quality of life [19]. Mental disorders, including anxiety and mood disorders, can be caused by prolonged avoidance of experiences (experiential avoidance), defined as an unwillingness to be involved with some aspects of experience or as a general lack of relational abilities [18, 20,21]. ACT provides an alternative perspective on difficult, unwanted personal events through acceptance [19], which involves an active and aware embracing of moment-to-moment personal experiences. Acceptance changes the function of experiential avoidance processes by enhancing a person's willingness to contact all their inner experiences (i.e. emotions, thoughts, bodily sensations), including the painful ones. ACT focuses on increasing psychological flexibility by developing six overlapping and interrelating core processes: acceptance, defusion, contact with the present moment, values, self as context, and committed action [18]. Interventions based on the psychological flexibility model facilitate a broad and flexible repertoire of responses to external and interoceptive clues and therefore can be used both in prevention and therapy. Cognitive fusion means responding to thoughts in terms of their literal content. On the contrary, cognitive defusion processes aim at suppressing the impact of verbally entangled inner experiences on the regulation of behaviour [22]. There is an array of cognitive defusion techniques aimed at changing a person's way of interacting with and relating to private vents. Reducing the literal quality of the thoughts is supported by attempts to perceive them as what they are, i.e. mental events that appear and disappear $[19,22,23]$. Mindfulness (contact with the present moment) based procedures may be regarded as strategies that restrict the avoidant repertoire. Therefore mindfulness is a type of defusion strategy that broadens the repertoire of responses with regards to external stimuli and inner experience as thoughts and feelings. The aware and non-judgmental experiencing moment-to-moment psychological events allows for the detachment from the verbally constructed description of the experience and fosters disengagement from typical avoidance approaches. Values foster engagement in committed action, which is nothing else but behavioural activation in the name of a chosen value [24]. The direction for ACT therapy is not in seeking pleasure but pursuing deeply held personal values. Incorporating values into treatment protocols can enhance a client's motivation to engage in actions that bring them closer to what they want their lives to stand for in different life domains. When barriers arise to 
Table 1. The training protocol

\begin{tabular}{|c|c|c|}
\hline Session & $\begin{array}{c}\text { Aim of the session/ACT processes/trained } \\
\text { psychological skill }\end{array}$ & Exercises/techniques/texts \\
\hline $\begin{array}{l}\text { 1. Introduction. } \\
\text { Setting goals. }\end{array}$ & $\begin{array}{l}\text { Case conceptualisation, psychoeducation: } \\
\text { introduction to the assumptions of ACT, contact } \\
\text { with the present moment, mindfulness. }\end{array}$ & $\begin{array}{c}\text { ACT case formulation worksheet, "Drop anchor" } \\
\text { exercise, "10 mindful breaths" exercise, } \\
\text { "Notice } 5 \text { things" exercise. }\end{array}$ \\
\hline 2. To be here and now. & $\begin{array}{l}\text { Contact with the present moment, mindfulness, } \\
\text { introduction into defusion, introduction to } \\
\text { the committed action, acceptance, willingness, } \\
\text { cognitive defusion. }\end{array}$ & $\begin{array}{l}\text { "10 mindful breaths" exercise, } \\
\text { "Mind as a time machine" metaphor, } \\
\text { "Mindfulness of breath" exercise, } \\
\text { analysing "What could change in your relations } \\
\text { if your life were to be free of pain and anxiety", } \\
\text { "Leaves on the stream" exercise, } \\
\text { "Mindfulness of pleasant activities". }\end{array}$ \\
\hline $\begin{array}{l}\text { 3. Understanding } \\
\text { difficult emotions. }\end{array}$ & $\begin{array}{l}\text { Psychoeducation: abandoning control, creative } \\
\text { hopelessness, psychoeducation: normalisation } \\
\text { of negative thinking in order to facilitate acceptance } \\
\text { and defusion, psychoeducation: our thoughts or } \\
\text { feelings are not a problem but our attitude towards } \\
\text { them (fusion or avoiding) and our thoughts and } \\
\text { feelings do not control our actions. }\end{array}$ & $\begin{array}{l}\text { "Control is the problem" text, } \\
\text { "The happiness trap" text, } \\
\text { "The caveman's mind" metaphor, } \\
\text { "The bin" exercise, } \\
\text { "Emotions are part of human experience" text. }\end{array}$ \\
\hline 4. Acceptance. & $\begin{array}{l}\text { Psychoeducation: giving up the struggle with difficult } \\
\text { thoughts and emotions, normalisation of difficult } \\
\text { emotions in life, creative hopelessness, acceptance, } \\
\text { cognitive defusion, contact with the present moment, } \\
\text { introduction into self-as-context. }\end{array}$ & $\begin{array}{l}\text { "Tug of war with monsters" metaphor, "Quicksand" } \\
\text { metaphor, "Emotions changing like a weather" } \\
\text { metaphor, "Your choice: decision to feel" text, } \\
\text { "I'm having the thought that..." exercise, "This feeling } \\
\text { is telling you..." text, "Struggle switch" metaphor, } \\
\text { "Observing \& breathing into the emotion" exercise, } \\
\text { "The mind as stage" metaphor. }\end{array}$ \\
\hline $\begin{array}{l}\text { 5. Observe your } \\
\text { thoughts. }\end{array}$ & $\begin{array}{l}\text { Cognitive defusion, contact with the present } \\
\text { moment, normalization of negative thinking in } \\
\text { order to facilitate acceptance and defusion, } \\
\text { psychoeducation: abandoning control, introduction } \\
\text { into the committed action. }\end{array}$ & $\begin{array}{l}\text { Observing thoughts, "Mindfulness of breath" exercise, } \\
\text { "Caveman mind" metaphor, "Overprotective friend" } \\
\text { metaphor, "I'm having a thought that..." exercise, } \\
\text { "Walk in the rain" metaphor. }\end{array}$ \\
\hline $\begin{array}{l}\text { 6. Thoughts do not } \\
\text { control our actions. }\end{array}$ & $\begin{array}{l}\text { Creative hopelessness, normalisation of negative } \\
\text { thinking, defusion, acceptance. }\end{array}$ & $\begin{array}{l}\text { "The inevitability of comparison" text, "If our thoughts } \\
\text { and feelings controlled our actions" text, "Leaves on } \\
\text { the stream" exercise, "Accepting emotions". }\end{array}$ \\
\hline $\begin{array}{l}\text { 7. To be in the present } \\
\text { moment. }\end{array}$ & $\begin{array}{c}\text { Contact with the present moment, defusion, } \\
\text { acceptance. }\end{array}$ & $\begin{array}{l}\text { "Drop anchor" exercise, "Mind as a time machine" } \\
\text { metaphor, "Mindfulness of the breath". }\end{array}$ \\
\hline $\begin{array}{l}\text { 8. Point of view - } \\
\text { to look at oneself } \\
\text { from a distance. }\end{array}$ & $\begin{array}{c}\text { Contact with the present moment, acceptance, } \\
\text { self-as-context, defusion. }\end{array}$ & "The chessboard" metaphor, "The Observer" exercise. \\
\hline $\begin{array}{l}\text { 9. Recognize what } \\
\text { is important. }\end{array}$ & $\begin{array}{l}\text { Contact with the present moment, acceptance, } \\
\text { defining values, psychoeducation: values. }\end{array}$ & $\begin{array}{l}\text { "Drop anchor" exercise, "The magic wand" exercise, } \\
\text { "Documentary about you" exercise, "10 aware } \\
\text { breaths" exercise, Values -a list of questions about } \\
\text { values, "10 valued domains" exercise. }\end{array}$ \\
\hline 10. Closer to values. & $\begin{array}{l}\text { Values, contact with the present moment, } \\
\text { acceptance. }\end{array}$ & $\begin{array}{l}\text { Values - Hayes cards, "Drop anchor" exercise, } \\
\text { "Safe place" exercise. }\end{array}$ \\
\hline 11. Be present. & $\begin{array}{l}\text { Contact with the present moment, mindfulness, } \\
\text { cognitive defusion, self-as-context. }\end{array}$ & $\begin{array}{l}\text { "Mindfulness of the breath" exercise, } \\
\text { "Mindful listening to classical music" exercise," } \\
\text { Acceptance of emotions" text. }\end{array}$ \\
\hline $\begin{array}{l}\text { 12. Act according to } \\
\text { values. }\end{array}$ & Values, acceptance, committed action. & $\begin{array}{l}\text { "Safe place" exercise, "The role of values" text, } \\
\text { "The valued areas of life" exercise, } \\
\text { "Values are here and now" exercise. }\end{array}$ \\
\hline
\end{tabular}

the fulfilment of actions according to their value in the specific domain, they are targeted with exposure and defusion strategies aimed at broadening the repertoire of flexible responses to those barriers by embracing and accepting the whole of the experience [24]. Committed action is a process linked to values-based action, which leads to more flexible behavioural patterns [19]. Additionally, ACT fosters a new perspective of self, a transcendent sense of self, which is experienced in the present moment $[19,22]$. It helps to undermine a judgmental, verbally constructed sense of self. In ACT, contrary to traditional CBT interventions, negative beliefs about self are not confronted and challenged. They are explained as personal events that sometimes appear and are experienced but are not identifying characteristics. Thus ACT interventions target not the form and content of the self-identifying thoughts but rather undermine attachment to them [25]. Self as context is fostered in ACT 
because it allows for the awareness of inner experiences without attachment to them [19]. Previous studies on interventions based on ACT have brought promising results [22, 25-31]. There is also some Polish literature regarding ACT as a potential tool for enhancing adaptive functioning [32, 33]. Programmes based on ACT are in line with the transdiagnostic approach [5], which emphasises that components of psychopathology are present across DSM-categorised disorders [34]. ACT interventions do not target problematic symptomatology directly, but they focus on developing processes that foster acceptance and change, which in turn may lead to valued living and the lowering of the level of psychopathological symptoms. Anxious symptomatology and worrying are present across DSM-described disorders and are the core symptoms in GAD. Worrying is regarded as an avoidance strategy, being a vulnerability and a maintenance factor of GAD [31]. In ACT-based interventions experiential avoidance is targeted by fostering psychological flexibility, so that patients with GAD symptoms might be the potential recipients of this kind of help. Due to the prevalence of undiagnosed mental disorders and the vast number of severe but sub-threshold manifestations of problematic symptomatology and obstacles to reaching comprehensive therapies [35], there is an exigency to implement quick and effective preventive procedures in primary care facilities, followed by referral to self-help evidence-based treatment interventions. This study exemplifies the effectiveness of intervention based on the ACT model as a potential treatment method.

\section{CASE DESCRIPTION}

A female, aged 52, residing in a small town, in high unemployment area, with financial difficulties and facing barriers to accessing the psychological health support system. Married, husband addicted to alcohol, 3 daughters. Family of origin of the respondent: two brothers (12 and 16 years older than herself) and a 17-year-older sister. In childhood, the patient experienced a difficult relationship with her mother. She reported that her emotional needs had never been fulfilled by her mother, a teacher at the local school. Additionally, her mother used physical violence against her. In childhood, the mother forced the patient to eat, but at the same time repeated inconsistently that she would be "fat" and that she did not look well. The patient's father was an abuser of alcohol - he was quiet and calm after drinking. Both brothers of the patient were alcoholics, but one of them has been sober for many years. At the age of 19, the patient got married. The reason was pregnancy. Her mother opposed the marriage. She commented on her daughter's pregnancy, "for a dog to take, a bitch must give". In adult life, the patient regulated her emotions by compulsive overeating, which led her to a state of morbid obesity.
After a stomach surgery and a few years of dieting, she reached a BMI of 27 . At 46 she lost her youngest daughter to suicide. The patient went without psychotherapeutic care, with only one visit to a psychologist in the hospital after the stomach surgery, and a one-off visit to a psychiatrist who prescribed pharmacotherapy (Sertraline, Hydroxyzine) continued in consultation with GP for four years. In 2019, the patient volunteered for the free programme supported financially by her local public administration and the EU funds delivered by a public benefit organization. The initiative aimed at aiding individuals, mainly senior, endangered with poverty and social exclusion. The patient was accepted for participation in the programme as a person at risk of social exclusion with serious health problems. The recipients of the program were encompassed within the programme's psychological counselling. The patient agreed that her case could be presented in a scientific article and signed the informed consent form. The initial interview was carried out by the psychologist employed by the public benefit organization, with the use of a semi-structured interview, and the ACT case formulation worksheet [23] was deployed to formulate case conceptualisation. The patient complained about resignation thoughts, difficulties in relations with her addicted husband, and reported emotional pain after losing her daughter. She refused to contact a psychiatrist ("it's too expensive; long queues for a free visit"). The woman had a sense of "closing in on herself". At the time of the examination, she lived with her husband, daughter and three granddaughters. She reported worrying about the insecure and unstable social and financial conditions of her family. She felt worthless and was overwhelmed by helplessness. Her expectations of therapy were connected with emotional goals like feeling peaceful and less powerless in helping her daughter and granddaughter, and "dead person goals" like not suffering when remembering and missing her late daughter. The aim of the intervention was to increase the psychological flexibility of the patient. The initial interview was followed by the formulation of the case conceptualisation. In order to assess the patient's psychopathological symptoms and psychological processes, she was examined before and after the treatment programme with the use of the following questionnaires: the Worry and Anxiety Questionnaire II (WAQ-II) in the Polish language version by Chojak and Papińska (2020), the Depression and Anxiety Scale short version (DASS-21) [36] in the Polish language version by Makara-Studzińska, Petkowicz, Urbańska and Petkowicz (2013), the Polish version of the Acceptance and Action Questionnaire (AAQ-II) by Dudek, Bond, Kleszcz, Białaszek and Ostaszewski [37], the State-Trait Anxiety Inventory (STAI) questionnaire by Wrześniewski, Sosnowski, Jaworowska and Fecenec [38], and the Valued Living Questionnaire (VLQ) in Polish language by Wytykowska and Chojak (2020). We 
present a short description of the measurement tools used below. The WAQ-II is a 13 -item self-report screening instrument. It was developed for the rapid assessment of GAD, for assessing the severity of GAD symptoms, and for measuring changes in GAD symptoms over the course of psychotherapy. Having thoroughly reviewed the literature of GAD, the simple definition of "worry" is given at the beginning of the questionnaire, which is considered to have minimal overlap with obsessive thoughts and depressive rumination. The first question on the WAQ-II asks respondents to list up to eight worry themes so that the clinician can receive information about the nature of the patient's worrying (GAD or non-GAD). All the remaining items of WAQ-II measure symptoms on a 9-point Likert scale. To meet the GAD criteria on the WAQ-II, respondents are required to give a response of at least 4 on the first three cognitive items, to three of the six somatic items and on the distress or the interference items. An important strength of the WAQ-II is that it can be scored either continuously or categorically. Scoring continuously can be helpful in assessing change over the course of psychotherapy. The WAQ-II is used in order to assess the presence of excessive worrying, the time frames in which the individual struggles with worries and the degree to which worrying disturbs daily functioning. The DASS- 21 is based on a dimensional conception of mental disorder which defines psychopathological symptoms as being present also in nonclinical populations but in milder forms. Emotional syndromes like depression and anxiety vary along a continuum of severity (independent of the specific diagnosis). Thus the DASS- 21 enables the useful assessment of disturbance, especially for individuals who may suffer from sub-threshold manifestations of a specific disorder. It is a self-report tool, widely used to assess symptoms of mental suffering in clinical and non-clinical adult samples, that was developed to measure depression, anxiety and stress signals over the previous week on three seven-item subscales. The authors of the tool agreed that the core symptoms of depression are low self-esteem, hopelessness, devaluation of life, self-deprecation and inertia. The main symptom of anxiety is physiological arousal, while the stress construct is comprised of items referring to difficulty relaxing, tension, impatience, irritability and restlessness. The answers are given on a 4-point Likert scale, which ranges from 0 if "I strongly disagree" to 3 if "I totally agree". Overall scores for the three constructs are calculated as the sum of scores for the relevant seven items. Cut-off scores correspond to the severity of symptoms, ranging from "normal" to "extremely severe". The STAI [38] questionnaire measures anxiety as a state (X-1 scale) and as a trait (X-2 scale) and contains 20 items for each scale. Questions on the X-1 scale refer to the current state of mind of the respondent, who marks the answers on a scale from 1 to 4 , where 1 means "defi- nitely not" and 4 means "definitely yes". The X-2 scale concerns the frequency of the feelings described in the items. The respondent marks the result on a scale from 1 to 4 , where 1 means "almost never" and 4 means "almost always". The higher score on the STAI, the higher level of anxiety. Psychological flexibility was measured via the Polish version of the Acceptance and Action Questionnaire (AAQ-II), which consists of 7 items. The higher the score, the lower the psychological flexibility. The VLQ [24] was used to measure values important to the client. The client underwent two sessions of questionnaire assessment: the first, before the intervention, in January 2020, and the second after the intervention in June 2020. The results of the first measurements are presented as follows. The client's results on the WAQ-II scored categorically showed that she meets the criteria for GAD. However, she had not been diagnosed before due to the financial and logistical barriers to accessing a mental health specialist. Her answers on the WAQ-II showed that the patient most often worried about health, family, her financial situation, and a sense of helplessness in everyday activities. The results in the initial DASS-21 measurement showed that the symptoms were "extremely severe" in the depression, anxiety and stress scales. The first measurement of the patient with the STAI questionnaire showed that the anxiety as a state was at a very high level (9-10 sten for $95 \%$ confidence interval) and anxiety as a trait indicated a result between 5 and 8 sten (for the $95 \%$ confidence interval). In the first measurement with the use of the AAQ-II, the client received the score of 43 , which indicated a low level of psychological flexibility. After pre-treatment measurements and the initial interview, the client took part in an intervention based on ACT. She was informed that during the sessions she would be taught new skills with which to handle painful thoughts and feelings more effectively so they would have less influence on her behaviour. The ACT case formulation worksheet allowed for the identification of the external barriers to a rich and full life (e.g. health issues, financial problems), fusion (with self-descriptions, rules and judgements) and important life domains and values of the patient. The training protocol (see Table I) was developed according to ACT guidelines [36] and included twelve 60-minute sessions delivered once per fortnight by a psychologist trained with ACT, with homework assignments to be fulfilled in the meantime and discussed on the following sessions. The protocol of the intervention is not a structuralised one and is based on metaphors and exercises chosen from the literature [39-42]. It is presented in the Annex 1. The choice of the exercises and metaphors was driven by the literature survey of the protocols for the treatment of anxiety $[22,31,43,44]$. The ACT case formulation was partially fulfilled in the first session and completed during the following meetings. In the period of social distancing caused by COVID-19 the interven- 
tion was conducted online. The procedure included sessions which targeted experiential avoidance, conceptualised as attempts to fix, control or avoid a certain form, frequency or situational sensitivity of private contingencies. The client was trying to avoid difficult thoughts and feelings by smoking and compulsive eating. When she put on weight excessively, she started to avoid social situations. The avoidance of social contexts was exacerbated by the belief that her family was perceived as "pathological". The pain caused by the unexpected tragic death of her daughter triggered excessive worrying about the life and health of the remaining daughters and the other family members. Worries extended also to financial and housing (renovation needed) issues. The client reported experiencing anxiety, constant irritation, sadness and remorse connected with her daughter's death, and a sense of despair. The first noticeable change in the patient's life was connected with the skill of emotion regulation. After the first two sessions the patient reported introducing the "Drop anchor" and "The 10 mindful breaths" exercises into her everyday routine and also doing them in moments of emotional arousal, which gave her a sense of relief and "looking from a distance". The psychoeducation and metaphors regarding excessive control over thoughts and feelings and exercises building creative hopelessness appeared in the third session. The patient analysed the strategies that she had used to control and get rid of difficult thoughts and feelings and calculated the costs generated by implementing these strategies. The "Tug of war with monsters" metaphor was used. The work on the following session was concentrated on the process of acceptance, which meant the patient embracing all her past and present experience non-judgementally. The acceptance exercises allowed her to shift her focus from reducing the psychological pain to living a valued life. The parallel process for strengthening acceptance incorporated into the following sessions was cognitive defusion, which undermines the behaviour regulation functions and directly impacts verbally described inner events [22]. The client struggled with thoughts such as "I have no reasons to live", "I'm responsible for my daughter's death", "People think that our family is insane", "We will not have enough money to survive", "Nothing good will happen in my life", "All the evil that happened to my family is divine retribution", and "The world is dangerous". Through metaphors and psychoeducation, the client was encouraged to change her relationship to thoughts and other private experiences in order to perceive them as mental events that appear and disappear one after another. For example, the client was encouraged to pick up a difficult thought and say "I'm having the thought that..." or notice a thought and let it go. The client's beliefs about herself were of this nature: "I am worthless", "I am fat and ugly", "I am stupid“, "I am unlovable", "I was a bad daughter and a bad mother". The intervention with the client included exercises and metaphors, which could help her to generate and foster a sense of self in which the content of consciousness was not threatening. The client reported being "less harsh" on herself in the following session. She realised that the words in her mind are only "labels" she had put on herself. She mentioned also that she thought that some of those labels were created by her mother. Although the training protocol from the very beginning included techniques which promoted contact with the present moment, such as mindful attention practices or breathing exercises, the crucial part of the work on this process took part on seventh session, with an extensive assignment including practising mindfulness techniques on a regular basis. As the patient had initially reported being overwhelmed by painful memories, difficult thoughts, crippling emotions and engaging in worrying on a regular basis; however, at the beginning of the eighth session she reported that she felt "being more present in her life" and experiencing it in the present moment instead of dwelling on the past or worrying about the future. The eighth session pertained to the self-as-context concept. The final sessions were focused on identifying the client's values and goals and promoting action in compliance with chosen values. The values identified by the client, measured with the VLQ, included family, friendship, education and personal development, career, spirituality, social life and physical well-being. The work on values was also done with the use of cards prepared by Louise Hayes [45]; the original texts were put onto the thematic photos chosen by the authors of this paper and displayed for the client. Subsequently, the client was encouraged to establish and pursue the goals that were tied to values and in this way her experiential avoidance (avoiding leaving home, social events, meeting friends, worrying, ruminating connected with her daughter's death) was reduced. The client expressed satisfaction with her participation in the programme. For the whole time during the intervention she was tried to perform assignments as recommended. She reported that although her life was still "full of current and old problems", she had learnt how to change her attitude towards them. She also emphasised that she would continue with mindfulness practice regularly. She reported being more relaxed and hopeful and admitted having a sense of compassion towards herself. She stated that she would recommend the programme to her friends. Apart from the conventional techniques and metaphors, the intervention was enriched by the use of visual aids displayed on the slide projector, including photos and graphics with quotations or short texts. These aids not only made the programme more attractive to the client but constitute ready-to-use material to include in a future self-help manual or mobile application. The mindfulness exercises were recorded in a professional studio and used 
during the intervention. Having completed the programme, the client took part in the second round of measurements. Her result on the AAQ-II as measured after the training (37) showed an increase in psychological flexibility when compared to the initial score (43). The results of the WAQ-II showed that the content of her worrying remained the same between the measurements, but there was a decrease in the intensity of worrying as compared to the first measurement. The post-intervention results on the WAQ-II scored categorically showed that the client did not fulfil the diagnostic criteria for GAD anymore, which is in line with the notion of a transdiagnostic approach to mental health, that the degree of intensity of psychopathological symptoms is the only differentiating factor with normalcy. The post-test WAQ-II result, scored continuously, showed an overall decrease from 66 to 50 points, indicating a lowering of the severity of the symptoms. The second measurement with the STAI questionnaire showed anxiety as a state at 5 and 7 sten (for the 95\% confidence interval), which indicates a decrease relative to the first measurement. The DASS- 21 total score declined after the intervention. The decline was observable on each of the three scales. The severity of symptoms decreased from "extremely severe" to "severe" on the depression and anxiety scales, and from "extremely severe" to "moderate" on psychological stress scale.

\section{COMMENT}

The article presents an example of the therapy of a patient with GAD undiagnosed prior to participation in the programme, who experienced chronic worry and anxiety as a state. Her problematic symptomatology, such as anxiety, depression and stress symptoms, was measured. Additionally, the level of psychological flexibility and the values of the patient were assessed. The intervention, based on ACT, was administered, and assessed in patient. The post-intervention results in the aforementioned questionnaires indicated a lowering of the psychopathological symptomatology and an increasing in psychological flexibility. The case study of the patient shows the potential of implementing mental health treatment interventions based on ACT as an evidence-based, effective and easy to administer method in individuals or groups from environments endangered with poverty or social exclusion. In this case study, difficult environmental and living conditions in a small town with a high unemployment rate, an alcohol-addicted husband, financial difficulties and barriers to accessing psychological help made the patient feel excluded from society. Her single contact with a psychiatrist and only one psychological consultation were not enough to reduce the experience of increasing suffering. ACT has been demonstrated to be effective in reducing problematic symptoms; nevertheless, the aim of the ACT-based interventions is not focused on lowering psychopathology but on increasing psychological flexibility. It provides clients with a panoply of skills facilitating a meaningful life according to one's chosen values. On the contrary to more conventional CBT therapies, it does not concentrate on changing problematic thoughts or behaviours (like core beliefs or automatic thoughts) but propagates the changing of the attitude towards inner experiences. Therefore, ACT does not concentrate on the content of the inner experience or its literal meaning but rather fosters understanding the understanding of experience in a situational context. It does not target a specific disorder with rigid protocols aimed at the concrete symptomatology, but rather provides a range of techniques and methods that reach the source of the problem, namely a lack of skills necessary for psychological flexibility. We suggest that the results of this case study could be replicated in groups of people in clinical and non-clinical trials in Polish conditions. We also suggest further quantitative research on the effectiveness of the ACT-based intervention, including web-based programmes or self-help treatment manuals, among people at risk of developing a mental disorder, and who demonstrate a severe level of problematic symptoms, but whose symptomatology is not sufficient to be classified as full-blown mental disorder, patients presenting anxious symptomatology, and patients suffering from GAD. The limitations of the study pertain to the lack of a larger group of researched people. The weakness to the implemented intervention were the time frames - the sessions were scheduled for once a fortnight, which could have implications for the therapeutic process. In the future implementation of the programme we suggest sessions should be conducted at least once a week as this would improve the consistency of the whole therapeutic process. Due to the COVID-19 restrictions, some of the sessions in this study were conducted online, which, according to the client's opinion, did not have any repercussions for the therapy process and outcomes. Based on the research in the literature $[19,22,25,32,40]$ and this case study, we suggest developing a self-help manual or mobile application with the intervention. This kind of intervention delivery offers advantages in availability and accessibility, which is crucial for individuals in need of psychological support from environments with barriers to accessing mental health care, such as remote villages or poverty- and social exclusion-endangered environments. ACT brings into practice the transdiagnostic approach to psychopathology, as the DSM or ICD categorical approach "denies an appropriate clinical status to early or milder symptom presentations, thus impeding preventing interventions" [46]. 


\section{Conflict of interest}

Absent.

\section{Financial support}

Absent.

\section{References}

1. Kessler RC, Petukhova M, Sampson N, Zaslavsky AM, Wittchen H. Twelve-month and lifetime prevalence and lifetime morbid risk of anxiety and mood disorders in the United States. Int J Methods Psychiatr Res 2012; 21: 169-184.

2. Greenberg PE, Birnbaum HG. The economic burden of depression in the US: societal and patient perspectives. Expert Opin Pharmacother 2005; 6: 369-376.

3. Wang PS, Aguilar-Gaxiola S, Alonso J, Angermeyer MC, Borges G, Bromet EJ, et al. Use of mental health services for anxiety, mood, and substance disorders in 17 countries in the WHO world mental health surveys. Lancet 2007; 370: 841-850.

4. Fani Marvasti F, Stafford RS. From sick care to health care-reengineering prevention into the U.S. system. N Engl J Med 2012; 367: 889-891.

5. Sharp PB, Miller GA, Heller W. Transdiagnostic dimensions of anxiety: neural mechanisms, executive functions, and new directions. Int J Psychophysiol 2015; 98: 365-377.

6. Meehl PE. Schizotaxia revisited. Arch Gen Psychiatry 1989; 46: 935-944.

7. Dugas MJ, Robichaud M. Cognitive-behavioral treatment for generalized anxiety disorder: from science to practice. New York: Routledge; 2007.

8. Hyman SE. The diagnosis of mental disorders: the problem of reification. Annu Rev Clin Psychol 2010; 6: 155-179.

9. Engels AS, Heller W, Mohanty A, Herrington JD, Banich MT, Webb AG, et al. Specificity of regional brain activity in anxiety types during emotion processing. Psychophysiology 2007; 44: 352-363.

10. Yehuda R, LeDoux J. Response variation following trauma: a translational neuroscience approach to understanding PTSD. Neuron 2007; 56: 19-32.

11. Insel TR, Cuthbert BN. Brain disorders? Precisely: precision medicine comes to psychiatry. Science 2015; 348 : 499-500.

12. Cuthbert BN, Kozak MJ. Constructing constructs for psychopathology: the NIMH research domain criteria. J Abnorm Psychol 2013; 122: 928-937.

13. Francis K, Dugas MJ. Assessing positive beliefs about worry: validation of a structured interview. Personality and Individual Differences 2004; 37: 405-415.

14. Borkovec TD, Alcaine OM, Behar E. Avoidance theory of worry and generalized anxiety disorder. In: Generalized anxiety disorder: advances in research and practice. Heimberg R, Turk C, Mennin D (eds.). New York: Guilford Press; 2004, p. 77-108.

15. Roemer L, Orsillo SM. Expanding our conceptualization of and treatment for generalized anxiety disorder: Integrating mindfulness/acceptance-based approaches with existing cognitive-behavioral models. Clinical Psychology: Science and Practice 2002; 9: 54-68.

16. Dugas MJ, Gagnon F, Ladouceur R, Freeston M. Generalized anxiety disorder: a preliminary test of a conceptual model. Behav Res Ther 1998; 36: 215-226.

17. World Health Organization. Global Burden of Mental Disorders and the Need for a Comprehensive, Coordinated Response from Health and Social Sectors at the Country Level. Geneva: World Health Organization; 2012.

18. Hayes SC, Strosahl KD, Wilson KG. Acceptance and commitment therapy: an experiential approach to behavior change. New York: Guilford Press; 1999.

19. Hayes SC, Luoma JB, Bond FW, Masuda A, Lillis J. Acceptance and commitment therapy: model, processes and outcomes. Behav Res Ther 2006; 44: 1-25.

20. Kashdan TB, Rottenberg J. Psychological flexibility as a fundamental aspect of health. Clin Psychol Rev 2010; 30: 865-878.

21. Bluett EJ, Homan KJ, Morrison KL, Levin ME, Twohig MP. Acceptance and commitment therapy for anxiety and OCD spectrum disorders: an empirical review. J Anxiety Disord 2014; 28: 612-624.

22. Twohig MP, Masuda A, Varra AA, Hayes SC. Acceptance and Commitment Therapy as a Treatment for Anxiety Disorders. In: Acceptance and Mindfulness-Based Approaches to Anxiety. Orsillo SM, Roemer L (eds.). New York: Springer; 2010.

23. Harris R. Zrozumieć ACT. Terapia akceptacji i zaangażowania w praktyce. Sopot: Gdańskie Wydawnictwo Psychologiczne; 2019.

24. Wilson KG, Murrell AR. Values work in acceptance and commitment therapy: setting a course for behavioral treatment. In: Hayes SC, Follette VM, Linehan MM (eds.). Mindfulness and acceptance: expanding the cognitive-behavioral tradition. New York: Guilford Press; 2004, p. 120-151.

25. Hacker T, Stone P, Macbeth A. Acceptance and commitment therapy - Do we know enough? Cumulative and sequential meta-analyses of randomized controlled trials. J Affect Disord 2016; 190: 551-565. 
26. Witlox M, Kraaij V, Garnefski N, De Waal MWM, Smit F, Hoencamp E, et al. An internet-based acceptance and commitment therapy intervention for older adults with anxiety complaints: study protocol for a cluster randomized controlled trial. Trials 2018; 19: 502 .

27. Kelson JN, Lam MK, Keep M, Campbell AJ. Development and evaluation of an online acceptance and commitment therapy program for anxiety: phase i iterative design. Journal of Technology in Human Services 2017; 35: 135-151.

28. Jacobs ML, Luci K, Hagemann L. Group-based acceptance and commitment therapy (ACT) for older veterans: findings from a quality improvement project. Clin Gerontol 2018; 41: 458-467.

29. Fledderus M, Bohlmeijer ET, Pieterse ME, Schreurs KM. Acceptance and commitment therapy as guided self-help for psychological distress and positive mental health: a randomized controlled trial. Psychol Med 2012; 42: 485-495.

30. Pots WTM, Fledderus M, Meulenbeek PAM, ten Klooster PM, Schreurs KMG, Bohlmeijer ET. Acceptance and commitment therapy as a web-based intervention for depressive symptomatology: randomised controlled trial. Brit J Psychiat 2016; 208: 69-77.

31. Roemer L, Orsillo SM, Salters-Pedneault K. Efficacy of an acceptance-based behavior therapy for generalized anxiety disorder: evaluation in a randomized controlled trial. J Consult Clin Psychol 2008; 76: 1083-1089.

32. Dudek J, Ostaszewski P, Białaszek W, Malicki S, Skarżyńska A. Związek elastyczności psychologicznej i spostrzeganej stygmatyzacji z satysfakcją z życia osób chorych na padaczkę: perspektywa terapii akceptacji i zaangażowania (ACT). Postępy Psychiatrii i Neurologii 2014; 23: 17-24.

33. Marcowski P, Białaszek W, Dudek J, Ostaszewski P. Higher behavioral profile of mindfulness and psychological flexibility is related to reduced impulsivity in smokers, and reduced risk aversion regardless of smoking status. Polish Psychological Bulletin 2017; 48: 445-455.

34. Behar E, DiMarco ID, Hekler EB, Mohlman J, Staples AM. Current theoretical models of generalized anxiety disorder (GAD): conceptual review and treatment implications. J Anxiety Disord 2009; 23: 1011-1023.

35. Andrade LH, Alonso J, Mneimneh Z, Wells JE, Al-Hamzawi A, Borges G, et al. Barriers to mental health treatment: results from the WHO World Mental Health (WMH) surveys. Psychol Med 2014; 44: 1303-1317.

36. Lovibond SH, Lovibond PF. Manual for the Depression Anxiety \& Stress Scales. $2^{\text {nd }}$ ed. Sydney: Psychology Foundation; 1995.

37. Kleszcz B, Dudek J, Białaszek W, Bond F, Ostaszewski P. Właściwości psychometryczne polskiej wersji Kwestionariusza Akceptacji i Działania-II (AAQ-II). Studia Psychologiczne 2018; 1: 1-20.

38. Wrześniewski K, Sosnowski T, Jaworowska A, Fecenec D. STAI - Inwentarz Stanu i Cechy Lęku. Polska adaptacja STAI. Warszawa: Pracownia Testów Psychologicznych PTP; 2011.

39. Forsyth JP, Eifert GH. The Mindfulness and Acceptance Workbook for anxiety. Oakland: New Harbinger Publications; 2016.

40. Harris R. The happiness trap: How to stop struggling and start living. Boston, MA: Trumpeter Books; 2008.

41. Hayes SC, Smith S. W pułapce myśli. Jak skutecznie poradzić sobie z depresją, stresem i lękiem. Sopot: Gdańskie Wydawnictwo Psychologiczne; 2019.

42. Hayes SC, Strosahl KD, Wilson KG. Terapia akceptacji i zaangażowania. Proces i praktyka uważnej zmiany. Kraków: Wydawnictwo Uniwersytetu Jagiellońskiego; 2013.

43. Wetherell JL, Liu L, Patterson TL, Afari N, Ayers CR, Thorp SR, et al. Acceptance and Commitment Therapy for generalized anxiety disorder in older adults: a preliminary report. Behav Ther 2011; 42: 127-134.

44. Boettcher J, Åström V, Påhlsson D, Schenström O, Andersson G, Carlbring P. Internet-based mindfulness treatment for anxiety disorders: a randomized controlled trial. Behav Ther 2014; 45: 241-253.

45. http://contextualpsychology.org/louise_hayes_training_page.

46. Hyman SE. The diagnosis of mental disorders: the problem of reification. Ann Rev Clin Psychol 2010; 6: 155-179. 